\section{Massimo Antonelli \\ Elie Azoulay \\ Marc Bonten \\ Jean Chastre \\ Giuseppe Citerio \\ Giorgio Conti \\ Daniel De Backer \\ Herwig Gerlach \\ Goran Hedenstierna \\ Michael Joannidis \\ Duncan Macrae \\ Jordi Mancebo \\ Salvatore M. Maggiore \\ Alexandre Mebazaa \\ Jean-Charles Preiser \\ Jerôme Pugin \\ Jan Wernerman \\ Haibo Zhang}

Received: 19 January 2011

Accepted: 19 January 2011

Published online: 3 February 2011

(C) Copyright jointly held by Springer and ESICM 2011

\section{Antonelli (®) - G. Conti •}

S. M. Maggiore

Department of Intensive Care and

Anesthesiology, Policlinico Universitario

A. Gemelli, Università Cattolica del Sacro

Cuore, Largo A. Gemelli, 8,

00168 Rome, Italy

e-mail: m.antonelli@rm.unicatt.it

Tel.: +39-06-30153226;

$$
\text { +39-06-30154386 }
$$

\section{E. Azoulay}

Intensive Care Medicine Unit,

Saint Louis Hospital, Paris, France

\section{Bonten}

Department of Medical Microbiology,

Julius Center for Health Sciences and

Primary Care University Medical Center,

Utrecht, The Netherlands

\title{
Year in review in Intensive Care Medicine 2010: III. ARDS and ALI, mechanical ventilation, noninvasive ventilation, weaning, endotracheal intubation, lung ultrasound and paediatrics
}

J. Chastre

Reanimation medicale, Hopital Pitié

Salpétrière, Paris, France

\section{G. Citerio}

Neurointensive Care Unit, Ospedale S.

Gerardo, Monza, Italy

D. De Backer

Service des Soins Intensifs,

Erasme Hospital, Brussels, Belgium

H. Gerlach

Department of Anesthesiology,

Vivantes-Klinikum Neukoelln,

Berlin, Germany

G. Hedenstierna

Department of Clinical Physiology,

Uppsala University, Uppsala, Sweden

\section{Joannidis}

Department of Internal Medicine,

Medical University of Innsbruck,

Innsbruck, Austria

D. Macrae

Pediatric Intensive Care Unit,

Royal Brompton Hospital,

London, UK
J. Mancebo

Intensive Care Medicine Unit,

Hospital Sant Pau, Barcelona, Spain

\section{A. Mebazaa}

Department of Anesthesiology and Critical

Care Medicine, Lariboisière Hospital,

Paris, France

J.-C. Preiser

Department of Intensive Care,

Erasme University Hospital,

Brussels, Belgium

J. Pugin

Intensive Care Medicine Unit,

University Hospital of Geneva,

Geneva, Switzerland

J. Wernerman

Departments of Anesthesiology and

Intensive Care Medicine,

Karolinska University Hospital,

Stockholm, Sweden

\section{H. Zhang}

Interdepartmental Division of Critical Care Medicine, University of Toronto,

Toronto, Canada

\section{ARDS and ALI}

In an observational, 4-month study performed in a reference centre in France, Roch et al. [1] compared characteristics, clinical evolution and outcome of adult patients with acute respiratory distress syndrome (ARDS) associated with influenza A (H1N1), treated with (nine patients) or without (nine patients) extracorporeal 
membrane oxygenation (ECMO). Before ECMO, patients had refractory respiratory failure $\left(\mathrm{PaO}_{2} / \mathrm{FiO}_{2} 52 \mathrm{mmHg}\right.$, $\mathrm{PaCO}_{2} 85 \mathrm{mmHg}$ ). Six ECMO treatments were initiated in the referral hospital by a mobile team. Patients treated with or without ECMO had the same hospital mortality rate $(56 \%)$. Duration of ECMO therapy was longer in survivors than in non-survivors (9 vs. 5 days). After ECMO initiation, early improvement of $\mathrm{PaO}_{2} / \mathrm{FiO}_{2}$ was greater in survivors than in non-survivors. Haemorrhagic complications occurred in $44 \%$ of ECMO patients, but none required surgical treatment. The conclusion was that ECMO may be an effective salvage treatment for patients with influenza A (H1N1)-related ARDS presenting rapid refractory respiratory failure, particularly when provided early in a specialized reference centre.

In an accurate meta-analysis Sud et al. [2] analysed the effects of prone versus supine ventilation in acute hypoxaemic respiratory failure (AHRF) and severe hypoxaemia $\left(\mathrm{PaO}_{2} / \mathrm{FiO}_{2}<100 \mathrm{mmHg}\right)$ compared with moderate hypoxemia $\left(\mathrm{PaO}_{2} / \mathrm{FiO}_{2}\right.$ between 100 and $300 \mathrm{mmHg})$. Ten trials $(N=1,867$ patients $)$ met inclusion criteria; most patients had acute lung injury. Methodological quality was relatively high. Prone ventilation reduced mortality in patients with $\mathrm{PaO}_{2} / \mathrm{FiO}_{2}$ below $100 \mathrm{mmHg}$ [risk ratio (RR) $0.84,95 \%$ confidence interval (CI) 0.74-0.96; $p=0.01$; seven trials, $N=555$ ] but not in patients with $\mathrm{PaO}_{2} / \mathrm{FiO}_{2}$ equal to or higher than $100 \mathrm{mmHg}$ (RR 1.07, 95\% CI 0.93-1.22; $p=0.36$; seven trials, $N=1,169)$. Post hoc analysis demonstrated statistically significant improved mortality in the more hypoxaemic subgroup and significant differences between subgroups using a range of $\mathrm{PaO}_{2} / \mathrm{FiO}_{2}$ thresholds up to approximately $140 \mathrm{mmHg}$. Prone ventilation improved oxygenation by $27-39 \%$ over the first 3 days of therapy but increased the risks of pressure ulcers (RR 1.29, 95\% CI 1.16-1.44), endotracheal tube obstruction (RR 1.58, 95\% CI 1.24-2.01) and chest tube dislodgement (RR 3.14 , 95\% CI 1.02-9.69). The authors concluded that prone ventilation reduces mortality in patients with severe hypoxaemia, but given the associated risks, the prone position should not be routine in all patients with AHRF, but may be considered for severely hypoxaemic patients.

Laminin-5, a cell adhesive molecule expressed solely by the epithelium, is known to enhance epithelial cell migration and repair of the injured epithelium. Its physiological role in alveolar epithelial injury remains unknown. The terminal gamma 2 fragment (G2F) of laminin-5 can be detected in the peripheral blood. Katayama et al. [3] examined the relationship between disease status and alveolar laminin-5 accumulation during the exudative phase in patients with acute lung injury (ALI), as reflected by circulating G2F levels. Sampling of epithelial lining fluids or pulmonary edema fluids from patients with acute lung injury ALI or related diseases was performed. Plasma samples were obtained from them at the time of disease onset or later. The authors found a significantly higher amount of G2F in pulmonary edema and epithelial lining fluids of patients with ALI, as compared with those with the other respiratory diseases. The plasma levels were also elevated significantly early at the onset of ALI (mean $\pm \mathrm{SD}, 147 \pm 82 \mathrm{ng} / \mathrm{ml}$ in non-surviving and $90 \pm 56$ in surviving patients) as compared with those in the patients with cardiogenic pulmonary edema $(59 \pm 36)$ or idiopathic pulmonary fibrosis $(37 \pm 17)$. At 5 days after onset, non-surviving patients maintained higher plasma concentrations $(152 \pm 84)$, but in contrast, the levels in surviving patients declined (71 \pm 35 ), suggesting secretion of laminin-5 was suppressed, associated with recovery from ALI. It was concluded that circulating G2F may be a useful biomarker to monitor the pneumocyte re-epithelialization process during alveolar repair in ALI patients.

Pulmonary hypertension is a characteristic feature of ARDS and contributes to mortality. Phosphodiesterases (PDE) inactivate cyclic GMP and thus relaxation of smooth muscle cell is inhibited. Cornet et al. [4] conducted a study to investigate whether sildenafil, which selectively inhibits the isoenzyme PDE5, is beneficial for patients with ARDS. Ten consecutive ARDS patients received a single dose of $50 \mathrm{mg}$ sildenafil via a nasogastric tube. Sildenafil decreased mean pulmonary arterial pressure from 25 to $22 \mathrm{mmHg}(p=0.022)$ and pulmonary artery occlusion pressure from 16 to $13 \mathrm{mmHg}$ $(p=0.049)$. Systemic mean arterial pressures were markedly decreased from 81 to $75 \mathrm{mmHg}(p=0.005)$. Sildenafil did not improve pulmonary arterial oxygen tension, but resulted in a further increase in the shunt fraction. It was concluded that the results did not justify a routine place for sildenafil in the treatment of ARDS patients. This article was accompanied by an editorial [5].

Transfusion of blood components is common in patients admitted to the intensive care unit (ICU) for gastrointestinal (GI) bleeding. However, the incidence and risk factors for development of transfusion-related acute lung injury (TRALI) in these patients are unknown. Data on 255 patients admitted to a medical ICU for GI bleeding and with specific risk factors for development of TRALI were analysed in a paper published in the October issue [6]. In transfused patients $(n=150)$, the incidence of TRALI was $15 \%$ and accounted for $76 \%(22 / 29)$ of all ALI cases. Transfused patients with end-stage liver disease (ESLD; $n=72$ ) developed TRALI more frequently than those without ESLD (29 vs. $1 \%, p<0.01)$. Fresh frozen plasma (FFP) was temporally associated with TRALI in $86 \%$ of cases. Transfusion-specific risk factors for development of TRALI included number of transfused units of FFP and non-leukoreduced red blood cells. Patient-specific risk factors included model for ESLD score, admission serum albumin level, and presence of ALI risk factors. It was concluded that TRALI is common in critically ill ESLD patients with GI bleeding. Nonleukoreduced red blood cells and FFP are significant 
transfusion-specific risk factors and their use should be reevaluated in these patients.

Acute respiratory failure might be a cause of ICU admission of pregnant and postpartum women. A systematic review of studies reporting the incidence and characteristics of these patients was published in the September issue [7]. A total of 40 eligible studies reporting outcomes for 7,887 women were analysed. All studies were retrospective with the majority reporting data from a single centre. The incidence of ICU admission ranged from 0.7 to 13.5 per 1,000 deliveries. Pregnant or postpartum women accounted for $0.4-16.0 \%$ of ICU admissions. Hypertensive disorders with acute respiratory failure were the most prevalent indication for ICU admission [median 0.9 cases per 1,000 deliveries (range $0.2-6.7)]$. There was no difference in the profile of ICU admission in developing compared to developed countries, except for the significantly higher maternal mortality rate in developing countries (median 3.3 vs. $14.0 \%, p=0.002$ ). Studies reporting patient outcomes subsequent to ICU admission are lacking. Pollock et al. [7] concluded that ICU admission of pregnant and postpartum women occurs infrequently. The ICU admission profile of women was similar in developed and developing countries; however, the maternal mortality rate remains higher for ICUs in developing countries. The ICU admission is potentially a useful indicator of severe maternal morbidity that captures data on women with the most severe disease.

Clinical applications of quantitative computed tomography (qCT) in patients with pulmonary opacities and ARDS are important, but are hindered by the radiation exposure and by the arduous manual image processing. Reske et al. [8] hypothesized that extrapolation from only ten thoracic CT sections will provide reliable information about the aeration of the entire lung. A retrospective analysis of CTs of 72 patients with normal and 85 patients with opacified lungs was done. Volumes and masses of the lung and its differently aerated compartments were obtained from all CT sections. Then only the most cranial and caudal sections and a further eight evenly spaced sections between them were selected. The results from these ten sections were extrapolated to the entire lung. The median (range) total lung volume was $3,738(1,311-6,768) \mathrm{ml}$, and the $95 \%$ limits of agreement were 26 ( -42 to 95$) \mathrm{ml}$. The median volumes (range) of differently aerated compartments (percentage of total lung volume) were $1(0-54) \%$ for the non-aerated, $5(1-44) \%$ for the poorly aerated, $85(28-98) \%$ for the normally aerated and $4(0-48) \%$ for the hyperaerated compartment. The agreement between the extrapolated results and those from all CT sections was excellent: the limits of agreement never exceeded $\pm 2 \%$. It was concluded that the extrapolation method can reduce radiation exposure and shorten the time required for qCT analysis of lung aeration and thus foster the application of the technique into research and clinical practice. This article has an editorial comment [9].

Giraud and co-workers [10] tested whether the monitoring of transpulmonary thermodilution curves can be used for detecting shunt. It is an interesting approach in which the authors tried to detect a vascular shunt between the arterial and venous side in the systemic circulation. Such shunt causes an early recirculation of the indicator. As a result of the low signal to noise ratio it can be difficult to detect early recirculation of the thermal indicator but it will also have an effect on the calculation of extravascular lung water (reflecting lung edema). By measuring obviously overestimated lung water, attention should be paid to the possible presence of a circulatory shunt (arteriovenous fistula?).

\section{Mechanical ventilation}

Ventilator performances and patient-ventilator interaction

Two studies evaluated performances of modern mechanical ventilators in specific conditions. In a bench study, Lyazidi et al. [11] assessed the performance of algorithms used by nine ICU ventilators to compensate for the volume compressed into the circuit and evaluated the accuracy of tidal volume delivered during volume-controlled ventilation. Measurements were performed under different conditions of respiratory mechanics, taking also into account humidity and temperature of the delivered gas. Delivered volume differed significantly across ventilators with an error range of -15 to $32 \%$ for set tidal volume, which represents $1-2 \mathrm{ml} / \mathrm{kg}$ for a preset tidal volume of $6 \mathrm{ml} / \mathrm{kg}$ predicted body weight. Respiratory system mechanics and application of an inspiratory pause significantly affected tidal volume actually delivered. Lyazidi et al. concluded that the difference between preset tidal volume and volume actually delivered is clinically meaningful and differs across modern ICU ventilators. In a multicentre randomized cross-over study, Vignaux et al. [12] evaluated the impact of noninvasive ventilation (NIV) algorithms available on modern ICU ventilators on the incidence of patient-ventilator asynchrony in 65 patients with acute respiratory failure. Although overall asynchrony was unchanged, the mean number of asynchronies influenced by leaks was significantly reduced by activating the NIV mode (from 28 to $12 \%$ without and with the NIV algorithm, respectively). In particular, ineffective efforts and late cycling significantly decreased, but some NIV algorithms tended to promote premature cycling. In conclusion, NIV algorithms provided by ICU ventilators can reduce the incidence of leakassociated asynchronies, while not necessarily changing the overall asynchrony. 
A new device, the PVI monitor, has been proposed to monitor and improve patient-ventilator interaction [13]. This device can calculate the patient's total inspiratory muscle pressure using estimated values of resistance and elastance of the respiratory system. Kondili et al. [14] evaluated the accuracy of the new device to quantify inspiratory muscle pressure by comparing values of total inspiratory muscle pressure measured using the transdiaphragmatic/esophageal pressure to those calculated by the PVI monitor in 11 patients ventilated with proportional assist ventilation plus. Values of inspiratory muscle pressure and inspiratory and expiratory time did not differ among the various methods of calculation. Inspiratory muscle pressure decreased with increasing the level of ventilator assistance, and the magnitude of this decrease did not differ among the various methods. Kondili et al. concluded that the PVI monitor may be used to provide breath-by-breath quantitative information about inspiratory muscle pressure in mechanically ventilated patients.

Synchrony between patient and ventilator strongly depends on settings and interfaces. Costa et al. [15] evaluated patient-ventilator interaction during pressure support ventilation (PSV) delivered with three interfaces: endotracheal tube (ET), face mask (FM) and helmet $(\mathrm{H})$. The study was performed at different pressurization times (Time (press)), cycling-off flow thresholds $(\operatorname{Tr}(\exp ))$ and respiratory rates in a bench study, and with FM and $\mathrm{H}$ in a healthy volunteers study. PSV was delivered through the three interfaces with three different respiratory rates in the bench study, and through FM and $\mathrm{H}$ at two different respiratory rates in the human study. The tested ventilator settings expressed as Time (press)/Tr (exp) were 50\%/ $25 \%$ (default setting), 20\%/5\% (slow setting) and $80 \% /$ $60 \%$ (fast setting). The patient-ventilator synchrony was significantly better with ET, with significantly lower inspiratory trigger delay and significantly higher time of assistance. The slow setting at respiratory rates of 30 breaths per minute produced the worst interaction, with higher rates of wasted efforts compared with the fast setting (20, 40 and 50\% of wasted efforts versus 0,16 and $26 \%$ of all spontaneous breaths, with ET, FM and H, respectively; $p<0.01$ ). In both studies the FM resulted in better synchrony as compared with the $\mathrm{H}$. It was concluded that patient-ventilator synchrony was significantly better with the ET than with the FM or $\mathrm{H}$ in the bench study. In vivo, the FM outperformed the $\mathrm{H}$ and fast settings can correct some of the limitations in terms of synchrony.

\section{Modes of ventilation}

Bilevel positive airway pressure ventilators, commonly employed to deliver NIV, use single-limb tubing which can increase the amount of $\mathrm{CO}_{2}$ rebreathing. Szkulmowski et al. [16] measured the amount of rebreathing with such ventilator circuits and assessed predictive factors for $\mathrm{CO}_{2}$ re-inhalation in patients receiving PSV, either through an endotracheal tube or with a NIV mask. Only $19 \%$ of the measured cycles had an inspired fraction of $\mathrm{CO}_{2}$ greater than $0.1 \%$. Four parameters were able to predict $\mathrm{CO}_{2}$ rebreathing: high end-tidal $\mathrm{CO}_{2}$, low positive end-expiratory pressure (PEEP), intubation and high respiratory rate. These results suggest that the risk of rebreathing with bilevel ventilators in the clinical setting is modest; application of PEEP and avoidance of high respiratory rates can further decrease this risk.

Several studies evaluated new ventilatory modes and techniques. Isgrò et al. [17] described a new continuous positive airway pressure (CPAP) system equipped with an electromechanical expiratory valve designed to switch between two PEEP levels on a time-cycled basis. By using such a device, the authors investigated the effects on oxygenation of applying a sigh (2 high pressure breaths per minute) or a biphasic positive pressure ventilation (10 mandatory breaths per minute) in patients with hypoxic respiratory failure undergoing continuous flow CPAP with a helmet. As compared with CPAP alone, the application of periodic sighs and biphasic positive airway pressure (BIPAP) induced a similar improvement in oxygenation which was maintained for at least $1 \mathrm{~h}$ after returning to standard CPAP. Isgrò et al. concluded that periodic, non-synchronized higher pressure breaths delivered at a rate as low as 2 breaths/min may improve oxygenation during helmet CPAP in hypoxaemic patients. Iotti et al. [18] reported the results of a multicentre, crossover trial performed to assess the shortterm effects of adaptive support ventilation (ASV) as compared with conventional volume or pressure-control ventilation in 88 patients with acute respiratory failure undergoing total ventilatory support. As compared with conventional ventilation and at the same minute ventilation, ASV resulted in a slightly lower $\mathrm{PaCO}_{2}$ without changes in oxygenation. During ASV, respiratory rate was slightly lower and tidal volume slightly greater than conventional ventilatory modes, especially in patients with obstructive disease. The ventilatory patterns selected by ASV were similar to those chosen by the clinicians during conventional ventilation: tidal volume was lower in patients with restrictive disease and expiratory time was prolonged in obstructed patients. With ASV, tidal volume was, however, unacceptably high in $11 \%$ of chronic obstructive pulmonary disease patients. Iotti et al. concluded that, as compared with conventional ventilation, ASV resulted in a similar ventilatory pattern and, in $35 \%$ of patients, in a more efficient $\mathrm{CO}_{2}$ elimination. González et al. [19] performed a case-matched analysis according to a propensity score to compare characteristics and clinical outcomes of 234 patients receiving airway pressure release ventilation (APRV) or BIPAP with those of 1,228 patients ventilated with assist-control ventilation (A/C) only. APRV/BIPAP was used only in selected 
geographic areas (84\% patients in Germany). Patients were less likely to be ventilated with APRV/BIPAP in the case of coma or congestive heart failure, $\mathrm{pH}<7.15$ prior to mechanical ventilation, and respiratory failure developing after intubation. No differences in clinical outcomes were observed between groups.

A novel adaptive control system for noisy pressurecontrolled ventilation was proposed in "a numerical simulation and bench test study" by Gama de Abreu's research group [20]. They developed and evaluated a control system based on the least-mean-squares adaptive approach that enables an automatic and continuous adjustment of the driving pressure during pressure-controlled ventilation to achieve desired variability in the tidal volume. Their conclusion is that the control system works under model experimental conditions, which is obviously a step before the clinical testing. It should be emphasized that the same group has demonstrated a number of advantages using noisy ventilation with improved respiratory mechanics and gas exchange.

ECMO can support oxygenation and carbon dioxide elimination in severe lung failure. Usually it is accompanied by controlled mechanical ventilation. Neurally adjusted ventilatory assist (NAVA) may allow a close interaction between ventilation and extracorporeal perfusion. In a pilot study, Karagiannidis et al. [21] intended to measure the physiologic ventilatory response in patients with severe lung failure treated with ECMO and NAVA. The authors hypothesized that the combination of both methods could automatically provide a protective ventilation with optimized blood gases. A case series of six patients treated with ECMO for severe lung failure is described. Tidal volumes on ECMO ranged between 2 and $5 \mathrm{ml} / \mathrm{kg}$ predicted body weight and increased up to $8 \mathrm{ml} / \mathrm{kg}$ with inactivated ECMO. Ventilatory response to decreased sweep gas flow was rapid, and patients immediately regulated $\mathrm{PaCO}_{2}$ tightly towards a physiological $\mathrm{pH}$ value. Increase in minute ventilation was a result of increased breathing frequency and tidal volumes. It was concluded that combination of NAVA and ECMO may permit a closed-loop ventilation with automated protective ventilation.

High-frequency oscillation (HFO) and tracheal gas insufflation (TGI) are employed in patients with ALI/ ARDS to enhance oxygenation and $\mathrm{CO}_{2}$ elimination. Mentzelopoulos et al. [22] compared HFO with and without TGI at the same mean tracheal pressure, to assess whether TGI can improve gas exchange independently from tracheal pressure. Two levels of mean tracheal pressure were studied. HFO with TGI resulted in better oxygenation (at both mean tracheal pressures) and lower $\mathrm{PaCO}_{2}$ (at the higher level of tracheal pressure) than HFO alone. The authors concluded that, at equal level of tracheal pressure, combining HFO with TGI resulted in better gas exchange than standard HFO. High-frequency percussive ventilation (HFPV) has been suggested to be beneficial in ARDS patients. Lucangelo et al. [23] performed a bench study in a bicompartmental mechanical lung model to assess whether and how varying the resistive and elastic loads applied to one compartment only would modify gas distribution between the two pathways under HFPV and pressure-controlled ventilation. With HFPV, hyperinflation was prevented and tidal volume was reduced. Gas distribution between the two compartments differed according to the ventilatory mode: unlike pressure-controlled ventilation, gas distribution with HFPV was not determined by the time constant of each compartment. In conclusion, HFPV accommodated volume distribution without overinflating compartments with low time constants, thus possibly presenting a potential protective behaviour in mechanically heterogeneous lungs.

\section{Noninvasive ventilation}

Several studies were dedicated to NIV. Phua et al. [24] evaluated the role of NIV in acute respiratory failure associated with bronchiectasis: the authors retrospectively reviewed bronchiectatic patients placed on NIV $(n=31)$ or invasive mechanical ventilation (IMV; $n=26$ ) for acute respiratory failure over 8 years. At baseline, the NIV group had more patients with acute exacerbations without identified precipitating factors (87.1 vs. $34.6 \%$ ), higher $\mathrm{pH}$ (mean 7.25 vs. 7.18) and $\mathrm{PaO}_{2} / \mathrm{FiO}_{2}$ ratio (mean 249.4 vs. 173.2, $p=0.02$ ), and a trend towards a lower APACHE II score than the IMV group. There was no difference in hospital mortality between the two groups ( 25.8 vs. $26.9 \%, p>0.05$ ). The NIV failure rate was $32.3 \%$. Using logistic regression, Phua et al. found that the APACHE II score was the only predictor of hospital mortality, and the $\mathrm{PaO}_{2} / \mathrm{FiO}_{2}$ ratio was the only predictor of NIV failure.

The possible role of small dead space heat and moisture exchangers (HME) during NIV was assessed in comparison with a heated humidifier $(\mathrm{HH})$ [25]. The effects of HME and $\mathrm{HH}$ on respiratory rate, minute ventilation, $\mathrm{EtCO}_{2}$, oxygen saturation, airway occlusion pressure at $0.1 \mathrm{~s}$, arterial blood gases $(\mathrm{ABG})$, and comfort perception were compared during two randomly determined NIV periods of $30 \mathrm{~min}$. No difference was observed between HME and HH suggesting that if one decides to humidify patients' airways during NIV, one may do so with small dead space HME or HH without altering respiratory parameters.

Fartoukh et al. [26] evaluated the use of early intermittent NIV for acute chest syndrome (ACS) in adults with sickle cell disease in a pilot study. Seventy-one consecutive ACS episodes in 67 patients were randomly allocated to oxygen $(n=36)$ or NIV $(n=35)$ for 3 days in a medical step-down unit. Baseline respiratory rate and 
pain score were higher in the NIV group. NIV promptly lowered the respiratory rate, raised $\mathrm{PaO}_{2}$, and decreased alveolar-arterial oxygen gradient $(\mathrm{A}-\mathrm{a}) \mathrm{O}_{2}$, which remained unchanged with oxygen alone. $\mathrm{PaCO}_{2}$ significantly worsened only in the oxygen group. On day 3 , the groups did not differ regarding the proportion of episodes with normal $\mathrm{PaO}_{2}$. In the subgroup of patients with severe hypoxaemia, physiological variables also improved faster with NIV.

The use of NIV for diagnostic bronchoscopy using a new face mask was evaluated by Heunks et al. [27]. A commercially available full-face mask was modified to allow introduction of the bronchoscope without interfering with the ventilator circuit. Bronchoscopy with bronchoalveolar lavage was performed in 12 hypoxaemic non-ICU patients during NIV in the ICU. Oxygenation improved after initiation of noninvasive positive pressure ventilation. In all patients the procedure could be completed without subsequent complications, although in one patient $\mathrm{SpO}_{2}$ decreased until $86 \%$ during bronchoscopy. A microbiological diagnosis could be established in 8 of 12 patients with suspected infection.

The problem of sedation during NIV was evaluated by Clouzeau et al. [28] studying the use of target-controlled infusion (TCI) of propofol for sedation in patients with noninvasive ventilation failure due to low tolerance. Ten patients with NIV failure due to discomfort, agitation and/ or refusal to continue with this ventilatory support were included; seven had acute respiratory failure and three had acute hypercapnic respiratory failure. Patients were sedated by TCI of propofol during NIV sessions. Blood gas analysis, cardiorespiratory and ventilatory parameters, propofol concentration (Cpt) required, comfort and adverse events were recorded. NIV under TCI of propofol significantly improved arterial blood gas analyses; three patients required endotracheal intubation, two due to evolution of underlying disease and one because of a seizure disorder. Eight patients were discharged from the ICU and two died, suggesting that in a selected population, TCI of propofol can facilitate acceptance of NIV.

Mask intolerance and discomfort are factors related to NIV failure. Analgesia-based sedation has been proposed to manage NIV failure in patients with acute respiratory failure. Rocco et al. [29] aimed to assess the feasibility of remifentanil-based sedation in hypoxaemic acute respiratory failure (HARF) patients refusing to continue NIV for intolerance to two different interfaces: helmet and total face mask. Thirty-six patients with persistent severe HARF who complained of discomfort and asked for interruption of NIV session were prospectively studied. Patients started sedation with remifentanil $(0.025 \mu \mathrm{g} / \mathrm{kg} /$ $\mathrm{min} / \mathrm{kg}$ ) and the infusion rate was increased by $0.01 \mu \mathrm{g} /$ $\mathrm{kg} / \mathrm{min}$ every minute to a maximum of $0.12 \mu \mathrm{g} / \mathrm{kg} / \mathrm{min}$ to obtain patient comfort. Twenty-two out of 36 patients $(61 \%)$ continued the NIV treatment after the introduction of remifentanil infusion. In this success group, median (interquartile range, IQR) respiratory rate decreased from $34(31,37)$ to $24(20,26)$ per $\min (p<0.0001)$ and $\mathrm{PaO}_{2} /$ $\mathrm{FiO}_{2}$ ratio increased from $156(144,176)$ to $270(210$, $300) \mathrm{mmHg}(p<0.0001)$ after $1 \mathrm{~h}$ of NIV with remifentanil, either with a helmet or total face mask. Fourteen patients failed to continue NIV and were intubated after a mean of $2.5 \pm 2.3 \mathrm{~h}$; they showed a respiratory rate decrease from $35(30,38)$ to $27(25,35)$ per $\min$ $(p=0.02)$ and an inability to increase the $\mathrm{PaO}_{2} / \mathrm{FiO}_{2}$ ratio above $180 \mathrm{mmHg}$. The ICU mortality in the failure group patients was 50 versus $14 \%$ in the NIV success group $(p<0.05)$. It was concluded that a remifentanilbased sedation strategy is feasible and safe.

Continuous positive airway pressure ventilation with a helmet was evaluated in infants under 1 year by Milesi et al. [30]. Twenty-three infants with a median age of 5 (2-8) months were included. Helmet CPAP failed in two (9\%) patients. Stability or improvement occurred in 16 (70\%) patients. The pain and discomfort score was stable or improved in $22(96 \%)$. The authors concluded that the helmet was a satisfactory interface for CPAP delivery in young infants in more than two-thirds of the cases.

\section{Weaning}

Optimal weaning strategy was assessed by Cabello et al. [31] in a physiological comparison of three spontaneous breathing trials (SBTs) in difficult-to-wean patients. The study aim was to compare cardiovascular and respiratory responses to different SBTs in difficult-to-wean patients using T-piece and pressure support ventilation (PSV) with or without PEEP. Fourteen patients who were monitored with a Swan-Ganz catheter and had failed a previous T-piece trial were studied. Three SBTs were performed in random order in all patients: PSV with PEEP (PSVPEEP), PSV without PEEP (PSV-ZEEP), and T-piece. PSV level was $7 \mathrm{cmH}_{2} \mathrm{O}$, and PEEP was $5 \mathrm{cmH}_{2} \mathrm{O}$. Most patients succeeded in the PSV-PEEP (11/14) and PSVZEEP (8/14) trials, but all failed the T-piece trial. Patient effort was significantly higher during T-piece than during PSV with or without PEEP. Left ventricular heart failure was observed in 11 of the 14 patients during the T-piece trial. Pulmonary artery occlusion pressure and respiratory rate were significantly higher during T-piece than with PSV-PEEP and tidal volume was significantly lower during the T-piece trial. The authors' conclusion was that in a population of difficult-to-wean patients, PSV and PSV plus PEEP markedly modified the breathing pattern, inspiratory muscle effort, and cardiovascular response as compared with the T-piece. Rapid shallow breathing may occur at any time during SBTs, questioning the utility of a single determination of the rapid shallow breathing index (RSBI). Segal et al. [32] hypothesized that change in RSBI during SBT may more accurately predict successful 
extubation than RSBI determination at a point in time. The percent change in RSBI during a 2-h SBT in individual subjects was evaluated in a prospective manner. Seventy-two subjects were extubated. At $24 \mathrm{~h}, 63 / 72$ remained extubated (Extubation Success), and 9 were reintubated (Extubation Failure). Respiratory rate, tidal volume (VT) and RSBI were measured every $30 \mathrm{~min}$ during the 2-h T-piece SBT. Initial RSBI was similar in Extubation Success and Extubation Failure groups $(77.0 \pm 4.8,77.0 \pm 4.8, p=$ not significant), and RSBI tended to remain unchanged or decreased in the Extubation Success group. However, RSBI tended to increase in the Extubation Failure group because of either increased respiratory rate and/or decreased VT $(p<0.001$ for mean percent change RSBI over time). Only 7/63 subjects of the Extubation Success group demonstrated increased $\mathrm{RSBI} \geq 20 \%$ at any time during the SBT. In contrast, in the Extubation Failure group, RSBI increased in all subjects during the SBT, and eight of nine subjects demonstrated an increase greater than $20 \%$. Thus, with a 2-h SBT the optimal threshold was a $20 \%$ increase (sensitivity $=89 \%$, specificity $=89 \%$ ). Percent change of RSBI predicted successful extubation even when initial values were $\geq 105$. Segal et al. concluded that the change in RSBI is a marker of dynamic changes that occur during weaning that may improve the ability to predict extubation outcome.

The SBT relies on objective criteria assessed by the clinician. However, little is known regarding the patient's subjective perception of autonomous breathing. A prospective observational study in 211 mechanically ventilated adult patients successfully completing a SBT analysed this specific subject [33]. Patients were randomly assigned to be interviewed during this trial regarding their prediction of extubation success. The postextubation outcomes were compared in three patient groups: patients confident (confidents; $n=115$ ) or not (non-confidents; $n=38$ ) of their extubation success and patients not subjected to interview (control group; $n=58$ ). Extubation success was more frequent in confidents than in non-confidents (90 vs. $45 \% ; p<0.001 /$ positive likelihood ratio $=2.00$ ) or in the control group (90 vs. $78 \% ; p=0.04$ ). On the contrary, extubation failure was more common in non-confidents than in confidents (55 vs. $10 \% ; p<0.001 /$ negative likelihood ratio $=0.19)$. Logistic regression analysis showed that extubation success was associated with patient's prediction [odds ratio (OR) $(95 \% \mathrm{CI}) 9.2$ (3.74-22.42) for confidents vs. non-confidents] and with age [0.72 (0.66-0.78) for age 75 vs. 65 and $1.31(1.28-1.51)$ for age 55 vs. 65]. It was concluded that at the end of a sustained SBT, extubation success might be correlated with the patients' subjective perception of autonomous breathing.

Sedation during mechanical ventilation is common clinical practice in the ICU and has important implications for the duration of mechanical ventilation and weaning. In June Intensive Care Medicine published a meta-analysis [34] carried out to assess the effects of using dexmedetomidine (D) as a sedative and analgesic agent on length of ICU stay, duration of mechanical ventilation, risk of bradycardia, and hypotension in critically ill adult patients. The controls were placebo or an alternative sedative agent. A total of 2,419 critically ill patients from 24 trials were subject to meta-analysis. D was associated with a significant reduction in length of ICU stay (weighted mean difference -0.48 days, $95 \%$ CI -0.18 to -0.78 days, $p=0.002$ ), but not duration of mechanical ventilation, when compared with an alternative sedative agent. There was, however, significant heterogeneity in these two outcomes between the pooled studies. D was associated with increased risk of bradycardia requiring interventions in studies that used both a loading dose and maintenance doses greater than $0.7 \mu \mathrm{g} /$ $\mathrm{kg} / \mathrm{h}$ [relative risk (RR) 7.30, 95\% CI 1.73-30.81, $p=0.007]$. It was concluded that significant heterogeneity existed between the pooled studies, and that the limited evidence suggested that D might reduce length of ICU stay in some critically ill patients. However, the risk of bradycardia was significantly higher when both a loading dose and high maintenance doses of $\mathrm{D}$ were used.

Patients who require mechanical ventilation are at risk of emotional stress because of total dependence on a ventilator for breathing and they know that their ability to breathe depends on assistance from a machine. Because of the presence of an endotracheal tube, they cannot talk and it is extremely difficult for most of them to communicate their needs. The stress may negatively impact ventilator weaning and survival. Jubran et al. [35] analysed whether depressive disorders in patients being weaned from prolonged mechanical ventilation are linked to weaning failure and decreased survival. A prospective study of 478 consecutive patients transferred to a longterm acute care hospital for weaning from prolonged ventilation was undertaken. A clinical psychologist conducted the interview with patients. Of the 478 patients, 142 had persistent coma or delirium and were unable to be evaluated for depressive disorders. Of the remaining 336 patients, $142(42 \%)$ were diagnosed with depressive disorders. In multivariate analysis, co-morbidity score (OR 1.23, $p=0.007$ ), functional dependence before the acute illness (OR 1.70, $p=0.03$ ) and history of psychiatric disorders (OR 3.04, $p=0.0001)$ were independent predictors of depressive disorders. The rate of weaning failure was higher in patients with depressive disorders than in those without such disorders (61 vs. 33\%, $p=$ 0.0001 ), as was mortality ( 24 vs. $10 \%, p=0.0008)$. Jubran et al. concluded that the presence of depressive disorders was related to factors present before the onset of the acute respiratory failure and that patients with depressive disorders were more likely to experience weaning failure and death.

Weaning from prolonged mechanical ventilation may be also associated with mental discomfort. The same 
group of authors in another study investigated whether post-traumatic stress disorder (PTSD) occurs in patients after weaning from prolonged ventilation and determined whether a questionnaire administration would identify patients at risk for developing PTSD [36]. In a prospective longitudinal study, 72 patients were studied 1 week after weaning, and 41 patients were studied again 3 months later. An experienced psychologist conducted a structured clinical interview 3 months after weaning. To assess for the presence of PTSD-related symptoms, the post-traumatic stress syndrome (PTSS-10) questionnaire was administered 1 week after weaning and 3 months later. PTSD was diagnosed in $12 \%$ of patients 3 months after ventilator weaning. Patients who developed PTSD were more likely to have a previous history of psychiatric disorders $(p<0.02)$. A PTSS-10 score higher than 20 one week after weaning reliably identified patients who were diagnosed with PTSD 3 months later: sensitivity 1.0; specificity 0.76 ; area under the receiver-operating characteristic curve (AUC) 0.91. It was concluded that the development of PTSD was related to the presence of previous mental difficulties rather than the severity of the underlying critical illness. A PTSS-10 score higher than 20 one week after weaning identified patients diagnosed with PTSD 3 months later. This finding suggests that a simple questionnaire administered before discharge can identify patients at risk for developing PTSD. This article has an accompanying editorial comment [37].

\section{Endotracheal intubation and tracheostomy}

Endotracheal intubation is one of the most common procedures performed in the ICU and is associated with complications. Jaber et al. [38] conducted an investigation to determine whether the implementation of an intubation management protocol leads to the reduction of intubationrelated complications in the ICU. To that end, a beforeafter study was done in three medical-surgical ICUs in two university hospitals. All intubations performed during two consecutive phases (6 months each) were evaluated. An initial quality control phase was followed by a phase based on the implementation of an ICU intubation bundle management protocol. Primary endpoints were the incidence of life-threatening complications within 60 min after intubation (cardiac arrest, death, cardiovascular collapse and hypoxaemia). The intubation procedure in the intervention (protocol) phase $(n=121)$ was associated with significant decreases in both lifethreatening complications ( 21 vs. $34 \%, p=0.03)$ and other mild complications ( 9 vs. $21 \%, p=0.01$ ) compared with the control phase $(n=123)$. No differences in other outcomes, such as ICU length of stay and mortality rates, were observed. The authors concluded that the implementation of an intubation management protocol can reduce immediate severe life-threatening complications.

Tadié et al. [39] assessed the rate of post-intubation laryngeal injuries and extubation failure in a prospective study including 136 patients extubated after more than $24 \mathrm{~h}$ of mechanical ventilation. Fibre-optic endoscopic examination of the larynx was systemically performed within $6 \mathrm{~h}$ after extubation in order to record four types of laryngeal anomalies: edema, ulceration, granulation and abnormal vocal cord mobility. Laryngeal injuries occurred in $73 \%$ of the study population and were associated with duration of intubation, absence of myorelaxants at intubation, emergency intubation and height/endotracheal tube size ratio. Seventeen patients were re-intubated within $48 \mathrm{~h}$ following extubation. Laryngeal examination of these patients more frequently showed granulation and abnormal pictures.

Many patients with respiratory failure related to neuromuscular disease receive chronic invasive ventilation through a tracheostomy. Improving quality of life, of which speech is an important component, is a major goal in these patients. The effects on breathing and speech of a low-level $\left(5 \mathrm{cmH}_{2} \mathrm{O}\right)$ PEEP, and of a Passy-Muir speaking valve (PMV) during assist-control ventilation was investigated in ten tracheotomized patients [40]. During speech with PEEP, six of the ten patients had no return of expiratory gas to the expiratory line and, therefore, had the entire insufflated volume available for speech, a condition met during PMV use in all patients. During speech, the respiratory rate increased by at least 3 cycles/min above the backup rate in seven patients with PEEP and in none of the patients with PMV. It was concluded that low-level PEEP is as effective as PMV in ensuring good speech quality.

\section{Lung ultrasound}

Lung ultrasound is a promising, noninvasive technique for lung and pleural pathology assessment in critically ill patients. Whole lung lavage is used to treat pulmonary alveolar proteinosis and can be considered as a complex human model of controlled lung de-aeration and its progressive resolution with PEEP application and diuretics administration. Via et al. [41] described ultrasound findings during whole lung lavage with validated semiotics and assessed their relation to the different states of lung aeration. During one-lung ventilation and saline flooding, ultrasound findings shifted from normal/nearly normal pattern and alveolar-interstitial syndrome to alveolar consolidation. Saline removal, re-ventilation and negative water balance were associated with a gradual return to alveolar-interstitial syndrome, then to a normal/nearly normal pattern. Arterial oxygenation variations were not always consistent with lung aeration changes. These 
findings showed that lung ultrasound could reliably describe the different states of aeration determined by the whole lung lavage procedure and confirmed ultrasound as an accurate technique for bedside monitoring of lung pathology.

Pleural effusions (PE) are frequent in the critically ill and accurate bedside quantification of the PE volume is challenging. Remérand [42] assessed the accuracy of a multiplane ultrasound approach to measure PE volume. The goal was to provide an accurate quantification of small to large PE and to help in the clinical decision making for thoracic drainage. The was study performed on 58 critically ill patients with 102 PEs and the PE was assessed using bedside lung ultrasound. Thoracic drainage was performed in 46 patients (59 PEs) and lung computed tomography (CT) in 24 patients (43 PEs). Ultrasound PE volume was compared with either the volume of the drained PE or PE volume assessed on lung CT. Ultrasound $\mathrm{PE}$ volume was correlated with drained $\mathrm{PE}$ volume $(r=0.84, p<0.001)$ and with CT PE volume $(r=0.90$, $p<0.001)$. Mean biases between ultrasound and actual volumes of $\mathrm{PE}$ were $-33 \mathrm{ml}$ when compared with drainage (limits of agreement -292 to $+227 \mathrm{ml}$ ) and $-53 \mathrm{ml}$ when compared with CT (limits of agreement -303 to $+198 \mathrm{ml}$ ). It was concluded that the multiplane approach increases the accuracy of lung ultrasound to measure the volume of large to small PEs and that this method can be recommended for the assessment of these PE.

\section{Paediatrics}

Respiratory

Whilst the focus of much research into the mechanisms of lung injury focus on the adult lung, we are reminded by both Sapru and Tissieres that lung injury occurs at all ages $[43,44]$. Sapru studied the relationship between increased plasma and pulmonary oedema fluid levels of plasminogen-activator inhibitor-1 (PAF-1), an anti-fibrinolytic agent which is activated during inflammation, and outcome of ALI in children. They demonstrated that as in adults, higher PAF-1 levels are associated with increased mortality and fewer ventilator-free days in children with ALI, suggesting that PAF-1 may serve as a useful biomarker of prognosis in children with ALI. Tissieres studied the effect of prophylactic surfactant on pulmonary outcomes in a group of very low birthweight infants. Previously, early lung recruitment (ELR) and high frequency oscillatory ventilation (HFOV) in combination with prophylactic surfactant were reported to reduce mortality and improve pulmonary outcomes. In this study, surfactant was only administered to those babies with unsatisfactory response to ELR. The rationale behind this approach is that (1) an easily recruitable lung in the early stage of RDS may not need exogenous surfactant treatment for sufficient lung opening and (2) gentle ventilation in an "open lung" may preserve surfactant function by avoiding a major inflammatory stimulus within the lungs, as suggested by experimental data. The authors showed that implementation of an ELR strategy with HFOV and selective surfactant administration resulted in no discernable detrimental effect on respiratory outcomes and mortality in VLBW infants presenting with RDS, raising the question of whether current practice of universal surfactant administration should be reconsidered. Ultimately, when considering the management of very severe respiratory failure in term neonates, ECMO has a wellestablished place. The report by Schaible [45] describes the outcomes of neonatal respiratory ECMO from a large European centre. Overall survival rates of $67 \%$ break down to $94 \%$ in babies with meconium aspiration and $62 \%$ in those with congenital diaphragmatic hernia. The report showed a clear association between early referral and higher rate of survival $77 \%$ survival for babies referred in the first $24 \mathrm{~h}$ of life compared with $54 \%$ for those referred at greater than $24 \mathrm{~h}$ of age).

Whilst much research focuses on biochemical and cellular mechanisms of lung injury and repair, important studies continue to emphasise to clinicians the importance of understanding lung physiology and the interactions of the lung with respiratory support systems. For example, Tingay et al. [46] described the impact of different endotracheal suction techniques on regional end-expiratory lung volume (EELV) and tidal volume in a surfactant-deficient piglet model. Closed suction (CS) methods and the use of smaller suction catheters have been claimed to result in less loss of recruitment during tracheal suction in neonates. Tingay compared open suction (OS) with two closed techniques when using either 5- or 8-French-gauge suction catheters. Their results question this, as recovery of lung volume and ventilation after endotracheal tube (ETT) suction was rapid and uniform throughout the lung with all suction techniques. Despite the 10- to 14-fold greater loss of EELV seen during OS, and CS with an 8-FG catheter compared with 5-FG CS, the regional EELV and $V_{\mathrm{T}} 10 \mathrm{~s}$ after suction did not differ. This rapid recovery is consistent with studies comparing global $\triangle E E L V$ during and after suction using open and closed methods and suggests that carefully conducted open suction remains a safe and effective option. Carlisle et al. [47] from the same research group also took a step back to basic physiology in exploring the influence of gravity on the distribution of ventilation and perfusion within the neonatal chest. Whereas it is widely recognised that the diseased adult lung is particularly prone to ventilation-perfusion mismatching, even when ventilation has been optimised, little is known about lung perfusion and the distribution of blood volume within the preterm lung. Traditional 
methods of determining lung perfusion, such as radionuclide scans, are not feasible in the ventilated neonate; however, the development of electrical impedance tomography (EIT) as a noninvasive, real-time, radiation-free method of measuring the relative change in impedances within regions of a cross section of the thorax facilitates the study of changes in gas, tissue and blood volumes. Air generates a greater impedance change than blood, and EIT has been used to measure regional ventilation in newborn infants with recent technological advances now enabling isolation of the EIT signal within the cardiac frequency domain thus allowing determination of cyclical changes in blood volume. Carlisle et al. demonstrated elegantly that gravity does indeed influence ventilation-perfusion relationships in the lungs of preterm infants, a finding which provides evidence to support clinical practice and future research including the use of positioning techniques and ventilatory strategies in the management of preterm lung disease.

In recent years, continuous positive airway pressure through nasal cannulae (nCPAP) provided to preterm neonates with respiratory failure has been shown to be effective in stabilizing proximal airways and surfactant-deficient alveoli, improving oxygenation, and to reduce the need for intubation. Infants who fail nCPAP may theoretically benefit from a noninvasive rescue ventilation. In a laboratory bench experiment, De Luca et al. [48] described the effect of nasal cannulae of varying diameter on the delivery of ventilation to a model lung using a widely used HFO ventilator. The authors concluded in this preliminary study that nasal prong diameter and flow are the main determinants of the delivered tidal volume and total ventilation. A great deal of additional bench and animal work will be required to further explore this potential extension to the noninvasive ventilatory armamentarium.

The outbreak of influenza A (H1N1) in the southern hemisphere during the summer of 2009 heralded similar surges of H1N1 infection in the northern winter of 2009-2010. Farias et al. [49] reported on the management and outcomes of 147 children admitted to paediatric intensive care units (PICUs) in Argentina during that period with H1N1 infection. Of those children, 94\% were invasively ventilated, with a reported mortality of $39 \%$. Of the children who died, whilst $59 \%$ suffered from a chronic medical condition, $41 \%$ were apparently previously healthy. This report is consistent with others in showing that the mortality rate from H1N1 influenza $A$ is higher than that usually recorded for seasonal influenza $\mathrm{A}$, and brings into focus the deaths of not only 'at risk' children, but those with no previous health concerns. Immunisation programmes need to take careful account of such reports.

Sepsis and multiorgan failure

Abdominal compartment syndrome (ACS), defined as a sustained intra-abdominal pressure (IAP) of greater than
$20 \mathrm{mmHg}$, is of concern because it is associated with multiorgan system failure and has a high mortality rate. Patient position and body mass index (BMI) affect intraabdominal pressure in adults and Ejike et al. [50] explored factors influencing IAP in 77 mechanically ventilated children less than 18 years of age. Paired measurements of IAP were measured in supine and $30^{\circ}$ head-up positions every $6 \mathrm{~h}$ over a 24-h period. Mean IAP was $10.6 \pm 4.0 \mathrm{mmHg}$ at $30^{\circ}$ head up, and $8.4 \pm 4.0 \mathrm{mmHg}$ in the supine position. No correlation was found between IAP and BMI or BMI percentiles. The authors concluded that whilst body position should be taken into account when interpreting IAP, BMI did not seem to influence IAP in their population of children and young people.

Peroxisome proliferator-activated receptor- $\gamma(\operatorname{PPAR} \gamma)$ is a ligand-binding nuclear receptor whose activation influences the inflammatory response. The mechanism of cytokine inhibition in activated monocytes/macrophages occurs, in part, through repression of several inflammatory response genes, including activator protein-1 and nuclear factor $-\kappa \mathrm{B}(\mathrm{NF}-\kappa \mathrm{B})$. The endogenous activator of $\operatorname{PPAR} \gamma, 15 \mathrm{~d}-\mathrm{PGJ}_{2}$, exerts beneficial anti-inflammatory effects, in part, through inhibition of NF- $\kappa \mathrm{B}$ activation and it is known that sepsis-induced reduction in PPAR $\gamma$ expression is reversed by in vivo treatment with PPAR $\gamma$ ligands. In a single-centre, prospective case-control study in critically ill children with systemic inflammatory response syndrome, sepsis or septic shock Kaplan et al. [51] determined that PPAR $\gamma$ nuclear protein expression was decreased but PPAR $\gamma$ activity was increased in peripheral blood monocytes from children with septic shock compared with controls. In addition, Kaplan investigated the effects of sepsis on $15 \mathrm{~d}-\mathrm{PGJ}_{2}$ and the downstream targets of PPAR $\gamma$ activity, high-molecularweight adiponectin (HMWA) and resistin [51]. Their results show that PPAR $\gamma$ activity on day 1 was significantly higher in patients with higher paediatric risk of mortality (PRISM) score compared with controls. Patients with resolved sepsis had increased levels of $15 \mathrm{~d}-\mathrm{PGJ}_{2}$ compared with patients with systemic inflammatory response syndrome (SIRS) and septic shock. In summary these findings suggest that sepsis is associated with altered PPAR $\gamma$ expression and activity in monocytes. Further studies are needed to understand the mechanisms underlying changes in PPAR $\gamma$ and their downstream targets in sepsis, as potential biomarkers or to inform therapeutic strategies. Sarafidis et al. [52] reported on the use of a potential biomarker, specifically serum soluble triggering receptor expressed on myeloid cells TREM-1, in the context of the early diagnosis of late-onset sepsis in neonates. S-TREM-1 and IL6 were measured when signs of sepsis were evident. Receiver operating curve (ROC) analysis for s-TREM-1 (AUC 0.733, $p=0.005$ ) compared favourably with IL-6 (AUC 0.892, $p=0.001$ ) for identification of infected neonates. There was, however, no statistically significant difference between the two 
biomarkers, and their deployment when sepsis was already suspected brings into question the general usefulness of the markers, given that clinical suspicion had already been aroused.

Agbeko et al. [53] sought to determine if common polymorphisms in the endotoxin recognition complex influenced the acute phase response as determined by the development of SIRS and platelet count on admission of children to critical care in a prospective observational cohort study. Paediatric intensive care patients $(n=913)$ were genotyped for common functional polymorphisms in the endotoxin recognition complex, including Toll-like receptor 4 (TLR4). TLR4 variant alleles were found to be associated with lower platelet counts across a range of ages and precipitating insults but that they do not influence the incidence of SIRS. This finding may reflect redundancy and 'robustness' in the pathways leading to SIRS or the lack of specificity of this endpoint. Platelet count may vary with TLR 4 genotype because it may be sufficiently sensitive and more linearly related to inflammation than other markers or, alternatively, there may be a direct TLR4-mediated platelet effect.

Two papers in the paediatric pages of Intensive Care Medicine reported new approaches to the characterisation and management of acute adrenal insufficiency in PICU. Dupuis et al. [54] reported a study in which serial blood cortisol and adrenocorticotropic hormone (ACTH) levels were measured in a series of 28 children with traumatic brain injury (TBI). Secondary adrenal insufficiency was defined as cortisol below $200 \mathrm{nmol} / \mathrm{l}$ with ACTH below $12 \mathrm{pmol} / \mathrm{l}$. Secondary adrenal insufficiency was detected in $10(37 \%)$ of children and was associated with a range of adverse clinical endpoints, raising the important question of whether cortisol replacement is needed in such TBI patients. A word of caution on measurement and interpretation of cortisol levels in critical illness is raised by Zimmerman [55] who points out that whilst historically adrenal function has been assessed by measuring total cortisol (TC) there is an evolving consensus that because free cortisol (FC) rather than protein-bound cortisol is responsible for the biochemical actions of this hormone the FC fraction should be measured as 'functionally important'. This is of particular relevance in critical illness as levels of cortisol-binding globulin and other proteins which bind cortisol such as albumin are altered. One practical drawback, however, is that the traditional assay method used to determine plasma-free cortisol, equilibrium dialysis, required large blood volumes and prolonged fractionation time preceding analysis. Zimmerman reported a pilot study on the measurement of FC using a chemiluminescence assay, determining that FC could be measured both accurately and rapidly (analyser time $38 \mathrm{~min}$ ) using the new assay method which requires only $0.4 \mathrm{ml}$ blood. Utilization of the new method for free FC analysis will require confirmation utilizing larger cohorts of both healthy and critically ill children but suggests that real-time FC quantification may be available to help guide clinical decision making regarding cortisol replacement therapy for children with critical illness.

Views on the usefulness of ECMO in shock are mixed. It is logical to suppose that in situations where cardiac dysfunction predominates as is the case in acute fulminant myocarditis, veno-arterial ECMO can be expected to support patients effectively. Enterovirus 71 (EV71) is usually a minor childhood illness, but can occasionally lead to cardiovascular collapse with acute cardiac involvement and cardiogenic shock. Jan and colleagues [56] reported a series of 13 cases of ECMO support in children with severe EV71 infection of whom 10 were successfully weaned from ECMO and survived. The median duration of ECMO support was $93 \pm 33 \mathrm{~h}$. Determining which patients to support with ECMO can be challenging, but in sepsis, focussing on cases with predominant cardiac involvement is recommended.

\section{Neurological critical care}

Head trauma is an important factor contributing to childhood morbidity and mortality. Injury is suffered in two distinct phases. The primary injury occurs at the moment of impact and results from mechanical forces that cause direct disruption of the brain parenchyma. The second phase of injury is a sequelae of events triggered by the primary injury and includes endogenous factors such as metabolic, cellular and biochemical derangements and exogenous factors such as hypoxia and hypotension. Over the last two decades, several studies have evaluated vasospasm in adult head trauma patients although the paediatric literature is extremely sparse. O'Brien [57] reported the results of a prospective observational study of 22 children with moderate or severe traumatic brain injury. Transcranial Doppler ultrasound examinations were performed to detect and follow vasospasm. Of the children examined, $45.5 \%$ developed vasospasm in the middle cerebral artery, and $18.2 \%$ in the basilar artery with onset typically on day $2-3$. The authors concluded that vasospasm, however, be an unrecognized phenomenon contributing to secondary brain injury in paediatric head trauma patients.

It has long been assumed that age and brain maturity have important influences on cerebral perfusion pressure (CPP) and autoregulation. Walter et al. [58] reported an experimental approach, in which a gradual reduction in CCP was induced, to estimate the threshold levels of increased glutamatergic and dopaminergic transmitter release responsible for excitotoxicity in newborn and juvenile pigs (i.e. the functional lower limit of cerebral autoregulation). The resulting effects on $\mathrm{CBF}$ and brain oxidative metabolism were quantified, and striatal 
glutamate and dopamine release were monitored by microdialysis. The authors showed an age-dependent threshold difference for significant extracellular glutamate and dopamine release following a gradual decrease in CPP. Juvenile pigs showed a marked elevation in the levels of both transmitters as early as at a moderate reduction of CPP, whereas this response was not apparent in newborn piglets which may suggest that the immature brain is less susceptible to damage through excitotoxic mechanisms than the more mature brain.

Hypoxia-ischaemia (HI) is a major cause of foetal brain damage and is effectively untreatable except in a supportive paradigm. Fathali et al. [59] provided an intriguing insight into a potential new therapeutic avenue for such babies in an investigation of the effect of granulocyte-colony stimulating factor (GCSF) on HI-induced brain damage in infant rats, following a 2 -h period of carotid ligation accompanied by hypoxia ( $8 \%$ oxygen). Compared with control animals, GCSF administered daily for 5 or 10 days following $\mathrm{HI}$ appeared to afford longterm neuroprotection assessed against both morphological and functional criteria. This interesting finding deserves further exploration in a clinical setting.

Parents are often frustrated at the inability of clinicians to accurately predict outcomes in paediatric neurointensive care. Carrai et al. [60] published a review of the literature on the use of somato-sensory evoked potentials (SEPs) in comatose children. The authors selected 14 studies covering 732 patients. In individual papers, the presence of SEP predicted favourable outcomes as shown by the area under both sROC curves being 0.958 . The same value was shown by SEP absence for predicting unfavourable outcomes. All covariates showed no significant effects on diagnostic accuracy, but only a slight non-significant trend. For SEP grading, a simple subgroup analysis showed a high positive predictive value (PPV) for non-awakening for absence of SEPs (PPV 97.0\%) and a high prognostic power to predict awakening for normal SEPs (PPV 92.2\%). Pathological SEPs did not show reliable predictivity. In children, the presence of SEPs showed a high prognostic power similar to that in adults. The study supports the use of SEPs in the integrated process of outcome prediction after acute brain injury in children. Caution is recommended in predicting unfavourable outcomes in patients with an absence of SEPs in both TBI and hypoxic-ischaemic encephalopathy (HIE) comas. The authors suggest that future studies are needed to resolve the issue of the effect of etiology and age on SEP's predictive power. This report is, however, an important snapshot of the current state of knowledge on the use of SEPs in paediatric coma.

The 'science' of improving outcome through better organisation or delivery of care is having a great impact in critical care units across the globe. For example the implementation of well-designed 'care bundles' aimed at for instance reducing nosocomial infection rates have been shown to be both clinically and economically effective. Decisions on where care is delivered and how it is delivered are important but must be informed by good data describing the population, the intervention or treatment and outcomes. Cogo et al. [61] investigated the outcomes from the care received by 1,265 Italian children admitted to adult intensive care units between 2003 and 2007 using data obtained from the 'Project Margherita' quality assessment and improvement database comparing these to a cohort of PICU children from 1994 to 1995. Using PRISM for risk adjustment, Cogo et al. found that the standardised mortality ratio was slightly worse for adult ICU care [1.11 (95\% CI 0.91-1.31)] than for PICU care [1.04 (95\% CI 0.88-1.19)]. The most important message from this paper is not, however, that promulgated by the author, i.e. that PICU care is best, but is rather that to measure performance in a healthcare system, prospective, relevant data are needed. Just as in clinical research, when measuring quality, safety, outcomes or managing cost, data is king.

Straney et al. [62] developed models to determine the efficiency of PICUs contributing data to the Australian and New Zealand Paediatric Intensive Care (ANZPIC) Registry which collects data from all of the nine specialist PICUs in Australia and New Zealand. Length of stay $(\mathrm{LoS})$ has been cited widely as a suitable marker for quantifying resource usage. However, efforts to compare LoS have been hampered by the difficulty in calibrating to case mix within centres and other local organisational factors. A method for quantifying variation of mean riskadjusted LoS among PICUs was recently reported by Rapoport et al. [63]. The Rapoport-Teres graph plots resource usage against clinical performance. It provides a simple and intuitive method for comparing efficiency among units and provides a visual representation of costeffectiveness. Using this technique, the authors demonstrated apparent differences in efficiency among PICUs which may be important for healthcare providers (PICUs) or healthcare commissioners to understand.

When assessing outcome for operational or research reasons, mortality is of only limited use in paediatric intensive care as the rate of mortality is now low and therefore use of death as an endpoint necessitates large sample sizes. The paediatric logistic organ dysfunction (PELOD) score was therefore developed as an outcome measure for clinical trials in the paediatric intensive care unit [64]. In the PELOD score markers of organ dysfunction are graded according to severity of derangement and assigned a score which is then summed in a composite score. The PELOD score has been validated in several populations in Europe and Canada, but Garcia et al. [65] recognised the importance of road-testing the PELOD score as widely as possible. They determined that the score performed well in discriminating between good and bad outcomes in children in their two Brazilian PICUs, although the score was poorly calibrated in their 
population (calibration of the score $=$ accuracy of observed vs. predicted outcomes). This paper, independent of the authors of the score, provides a useful insight into the undoubted strengths and some potential weaknesses of what they nevertheless conclude to be a useful additional PICU scoring tool.

Peeters et al. [66] prospectively examined the riskadjusted mortality of children admitted to a large Dutch intensive care PICU to determine whether 'out-of-hours' admission was associated with poorer outcomes than 'inhours' admission, given that the senior intensivists were not resident in the hospital out-of-hours. Of the 3,212 admissions studied, $66 \%$ occurred in-hours. No difference in standardised mortality rate was established between inand out-of-hours admissions in this single unit. This report adds to the literature which remains confusing with some of the few reports on this topic suggesting that hour of admission or the immediate presence of the most senior intensivist makes no difference, whilst others suggest that senior cover improves outcomes.

A strategy widely promoted over recent years in both adult and paediatric critical care is the use of 'alert' or 'early-warning' scores to detect deteriorating patients in non-ICU areas. Chapman et al. [67] systematically reviewed studies reporting paediatric alert criteria with assessment of their validity, reliability, clinical effectiveness and clinical utility. Eleven studies were included and described ten alert criteria. Only three of the five studies which published the predictive value of paediatric alert criteria reported appropriate methodology. Only one study evaluated reliability and no study addressed the clinical utility of paediatric alert criteria. The authors therefore had no difficulty in concluding that the evidence supporting the use of clinical use of paediatric alert criteria is weak and that prospective development and evaluation are needed before their widespread adoption into clinical practice.

Naghib et al. [68] reported the outcomes of children staying more than 28 days in a Dutch PICU. During the study period 2,607 patients were admitted on 3,700 occasions for a total of 16,013 admission days. Of this group $4.4 \%(116 / 2,607)$ of patients were identified as very long-stay patients, consuming $63 \%(10,055 / 16,013)$ of PICU admission days. Mortality in this group was 5 times higher $(22 \%)$ than that for the whole PICU population $(4.6 \%)$. The investigators reported that withdrawal or limitation of care preceded $70 \%$ of deaths. This study emphasises the large burden that prolonged intensive care dependency places on the child, their family and the healthcare system. There is a clear need to adopt strategies which promote rapid recovery and therefore reduce the need for long-term critical care status, but also a need to provide realistic options for limitation of critical care if after careful assessment and discussion children are no longer benefiting from intensive support.

\section{CPR}

The development of the scientific basis of cardiopulmonary resuscitation continues to evolve. Iglesias et al. [69] conducted a comparison of tidal volumes achieved with ventilation plus compressions (VC) versus chest compressions alone (CC) in 12 infant piglets after induced hypoxic cardiac arrest. VC achieved a similar tidal volume to calculated requirements, whereas tidal volume with $\mathrm{CC}$ was very low. The $\mathrm{VC}$ technique achieved a higher $\mathrm{pH}$ and $\mathrm{PO}_{2}$ and a lower $\mathrm{PCO}_{2}$ than $\mathrm{CC}$. The clinical relevance of these findings to clinical practice remains to be established, although there is some evidence that in the early stages of CPR effective CC alone may lead to better perfusion of vital organs.

Adrenaline is the recommended drug for the treatment of cardiac arrest (CA) both in children and adults based on its vasoconstrictive and inotropic effects. Vasopressin and terlipressin, a synthetic vasopressin analogue with a longer half-life, produce vasoconstriction by the stimulation of V1 receptors. Several studies have shown that vasopressin increases vital organ blood flow and cerebral oxygen delivery; in addition, adrenaline plus vasopressin achieved a higher return of spontaneous circulation (ROSC) and neurological recovery when compared with adrenaline alone in adult animals with CA secondary to ventricular fibrillation (VF). Initial clinical studies with vasopressin plus adrenaline were not found to improve the results in adult patients with ventricular fibrillation and pulseless electrical activity compared with adrenaline alone, but there was an improvement in the results of resuscitation in cases of asystole and refractory CA. Lopez-Herce [70] compared terlipressin with adrenaline in an animal model of paediatric asphyxial cardiac arrest. They determined only a non-significant trend towards better outcome when terlipressin was combined with adrenaline compared with either drug alone. Further evaluations of the role of vasopressin analogues in paediatric CPR are needed.

\section{Drug treatment}

Drug handling is notoriously difficult to predict in the paediatric critical care environment, as organ function deteriorates, extracorporeal technologies are deployed or critical interactions occur between drugs. Wildschut et al. [71] described a simple study in which a range of common PICU drugs including sedative, analgesics and antibiotics were added to a range of recirculating neonatal and paediatric ECMO circuits. Unsurprisingly, lipophilic drugs such as fentanyl were most likely to be highly absorbed by the ECMO circuit components, although some types of ECMO circuit bind less fentanyl than 
others. Morphine is less lipophilic and may therefore be the opioid of choice during ECMO. Another issue with drug delivery was highlighted by Jack et al. [72] who showed in a an elegant animal study that particulate contamination of infusion solutions can lead to biological derangements. The authors confirmed the existence of particulate contamination in infusions despite a stringent infusion regime. In vitro investigation of a number of inflammatory mediators demonstrated that particulate contaminants had the effect of suppressing macrophage and endothelial cytokine secretion. The importance of reducing particulate contamination to prevent immune modulation is recommended by the authors.

Two sedation studies in PICU populations were published in Intensive Care Medicine in 2010. Daily interruption of analgeso-sedatives has been recommended as a component of optimal care in adult critical care following the landmark paper from Kress et al. [73]. Wildschut et al. [74] reported on the feasibility of analgesia and sedation interruption in 20 neonates on ECMO. The prospective study was undertaken in a single PICU. Midazolam and morphine were discontinued after ECMO cannulations were completed and only restarted based on COMFORT-B and visual analogue pain nurse-observed scores. Time without morphine before restart was $10.25 \mathrm{~h}$ (IQR 5-24.1) and time without midazolam was $16.5 \mathrm{~h}$ (IQR 6.6-29.6). No accidental extubations, decannulations or bleeding occurred in patients undergoing sedation interruption. This study emphasises the surprisingly slow metabolism of analgo-sedative drugs in the sick neonate and should encourage the adoption of endpoint-related drug administration wherever possible, especially in critically ill neonates with organ dysfunction of critical illness potentially compounding organ immaturity. Chrysostomou et al. [75] reported a prospective observational study of the use of dexmedetomidine in 51 children in PICU with congenital heart disease (CHD). Dexmedetomidine is a highly selective alpha 2-agonist with sedative and analgesic properties that has been shown to reduce the postoperative requirements of additional intravenous sedative and analgesic agents. Dexmedetomidine mediates its effects through a complex mechanism that involves both presynaptic and postsynaptic receptor activation. Activation of the presynaptic alpha-2 adrenoreceptors on sympathetic nerves and the central nervous system induces sympatholysis, which is responsible for the hypotensive and bradycardic side effects. Although dexmedetomidine appears to have a wide safety margin, there have been concerns related to the development of sudden sinus node pauses, symptomatic bradycardia and its potential to cause atrio- ventricular nodal block and prolongation of the QTc interval. This study characterised the electrocardiographic (ECG) effects of dexmedetomidine in children with CHD and children undergoing cardiothoracic surgery. The principle findings of this detailed electrophysiological study showed that in the dexmedetomidine group, heart rate (HR) decreased from $140 \pm 22$ to $115 \pm 23$. When compared with the control group, none of the ECG intervals showed any difference other than a trend towards lower HR $(p=0.08)$. The use of dexmedetomidine in patients with CHD was not associated with any clinically significant ECG abnormalities.

\section{Endocrine and metabolic}

Plumpton et al. [76] characterised the thyroid hormone and cortisol concentrations in a prospective observational study of 52 infants younger than 3 months of age after congenital heart surgery. In brief, in this well-presented and data-rich study, infants with low triiodothyronine $(\leq 3.7 \mathrm{pmol} / \mathrm{l})$ or high cortisol concentration on postoperative admission to the PICU were more likely to have a high inotrope requirement on postoperative day 2 $(p=0.003$ and $p=0.0006$, respectively) or need mechanical ventilation for longer than $96 \mathrm{~h}(p=0.04$ and $p=0.002$, respectively). Total cortisol concentration less than $200 \mathrm{nmol} / \mathrm{l}$ was found in 16 (31\%) infants. Free cortisol levels were found to follow total cortisol levels closely in this study. There was no association between low cortisol and postoperative complications. The authors speculate on the relevance of these derangements in endocrine function and the potential to intervene with supplements to 'correct' the abnormalities [76].

Kyle et al. [77] presented a look-back report of the association between organ dysfunction and hyperglycaemia in 110 critically ill children. Organ dysfunction ( $\geq 3$ versus $<3$ organs) was significantly associated with hyperglycaemia for at least $24 \mathrm{~h}$ and hypoglycaemia. There was a trend towards increased mortality in the hyperglycaemic group. These findings are not surprising given the reports from many other ICU populations of similar associations. Whether a policy of permissive or tight glycaemic control should be deployed in the management of critically ill adults is not yet settled [78], and in the paediatric ICU there is only one published randomised controlled trial which is supportive of tight glycaemic control [79]. The results of the CHiP trial, a multicentre trial of tight glycaemic control versus 'usual' care, will complete recruitment in late 2011 [80]. 


\section{References}

1. Roch A, Lepaul-Ercole R, Grisoli D, Bessereau J, Brissy O, Castanier M, Dizier S, Forel JM, Guervilly C, Gariboldi V, Collart F, Michelet P, Perrin G, Charrel R, Papazian L (2010) Extracorporeal membrane oxygenation for severe influenza A (H1N1) acute respiratory distress syndrome: a prospective observational comparative study. Intensive Care Med 36:1899-1905

2. Sud S, Friedrich JO, Taccone P, Polli F, Adhikari NK, Latini R, Pesenti A, Guerin C, Mancebo J, Curley MA, Fernandez R, Chan MC, Beuret P, Voggenreiter G, Sud M, Tognoni G, Gattinoni L (2010) Prone ventilation reduces mortality in patients with acute respiratory failure and severe hypoxemia: systematic review and meta-analysis. Intensive Care Med 36:585-599

3. Katayama M, Ishizaka A, Sakamoto M, Fujishima S, Sekiguchi K, Asano K, Betsuyaku T, Kotani T, Ware LB, Matthay MA, Hashimoto S (2010) Laminin gamma2 fragments are increased in the circulation of patients with early phase acute lung injury. Intensive Care Med 36:479-486

4. Cornet AD, Hofstra JJ, Swart EL, Girbes AR, Juffermans NP (2010) Sildenafil attenuates pulmonary arterial pressure but does not improve oxygenation during ARDS. Intensive Care Med 36:758-764

5. Blanch L, Albaiceta GM (2010) Sildenafil for pulmonary hypertension in ARDS: a new pleasant effect? Intensive Care Med 36:729-731

6. Benson AB, Austin GL, Berg M, McFann KK, Thomas S, Ramirez G, Rosen H, Silliman CC, Moss M (2010) Transfusion-related acute lung injury in ICU patients admitted with gastrointestinal bleeding. Intensive Care Med 36:1710-1717

7. Pollock W, Rose L, Dennis CL (2010) Pregnant and postpartum admissions to the intensive care unit: a systematic review. Intensive Care Med 36:1465-1474

8. Reske AW, Reske AP, Gast HA, Seiwerts M, Beda A, Gottschaldt U, Josten C, Schreiter D, Heller N, Wrigge H, Amato MB (2010) Extrapolation from ten sections can make CT-based quantification of lung aeration more practicable. Intensive Care Med 36:1836-1844

9. Gattinoni L, Cressoni M (2010) Quantitative CT in ARDS: towards a clinical tool? Intensive Care Med 36:1803-1804
10. Giraud R, Siegenthaler N, Park C, Beutler S, Bendjelid K (2010) Transpulmonary thermodilution curves for detection of shunt. Intensive Care Med 36:1083-1086

11. Lyazidi A, Thille AW, Carteaux G, Galia F, Brochard L, Richard JC (2010) Bench test evaluation of volume delivered by modern ICU ventilators during volume-controlled ventilation. Intensive Care Med 36:2074-2080

12. Vignaux L, Tassaux D, Carteaux G, Roeseler J, Piquilloud L, Brochard L, Jolliet P (2010) Performance of noninvasive ventilation algorithms on ICU ventilators during pressure support: a clinical study. Intensive Care Med 36:2053-2059

13. Younes M, Brochard L, Grasso S, Kun J, Mancebo J, Ranieri M, Richard JC, Younes H (2007) A method for monitoring and improving patient: ventilator interaction. Intensive Care Med 33:1337-1346

14. Kondili E, Alexopoulou C, Xirouchaki N, Vaporidi K, Georgopoulos D (2010) Estimation of inspiratory muscle pressure in critically ill patients. Intensive Care Med 36:648-655

15. Costa R, Navalesi P, Spinazzola G, Ferrone G, Pellegrini A, Cavaliere F, Proietti R, Antonelli M, Conti G (2010) Influence of ventilator settings on patient-ventilator synchrony during pressure support ventilation with different interfaces. Intensive Care Med 36:1363-1370

16. Szkulmowski Z, Belkhouja K, Le QH, Robert D, Argaud L (2010) Bilevel positive airway pressure ventilation: factors influencing carbon dioxide rebreathing. Intensive Care Med 36:688-691

17. Isgrò $S$, Zanella A, Sala C, Grasselli G, Foti G, Pesenti A, Patroniti N (2010) Continuous flow biphasic positive airway pressure by helmet in patients with acute hypoxic respiratory failure: effect on oxygenation. Intensive Care Med 36:1688-1694

18. Iotti GA, Polito A, Belliato M, Pasero D, Beduneau G, Wysocki M, Brunner JX, Braschi A, Brochard L, Mancebo J, Ranieri VM, Richard JC, Slutsky AS (2010) Adaptive support ventilation versus conventional ventilation for total ventilatory support in acute respiratory failure. Intensive Care Med 36:1371-1379
19. González M, Arroliga AC, Frutos-Vivar F, Raymondos K, Esteban A, Putensen C, Apezteguia C, Hurtado J, Desmery P, Tomicic V, Elizalde J, Abroug F, Arabi Y, Moreno R, Anzueto A, Ferguson ND (2010) Airway pressure release ventilation versus assist-control ventilation: a comparative propensity score and international cohort study. Intensive Care Med 36:817-827

20. Beda A, Spieth PM, Handzsuj T, Pelosi $\mathrm{P}$, Carvalho NC, Koch E, Koch T, Gama de Abreu M (2010) A novel adaptive control system for noisy pressure-controlled ventilation: a numerical simulation and bench test study. Intensive Care Med 36:164-168

21. Karagiannidis C, Lubnow M, Philipp A, Riegger GA, Schmid C, Pfeifer M, Mueller T (2010) Autoregulation of ventilation with neurally adjusted ventilatory assist on extracorporeal lung support. Intensive Care Med 36:2038-2044

22. Mentzelopoulos SD, Malachias S, Kokkoris S, Roussos C, Zakynthinos SG (2010) Comparison of highfrequency oscillation and tracheal gas insufflation versus standard highfrequency oscillation at two levels of tracheal pressure. Intensive Care Med 36:810-816

23. Lucangelo U, Accardo A, Bernardi A, Ferluga M, Borelli M, Antonaglia V, Riscica F, Zin WA (2010) Gas distribution in a two-compartment model ventilated in high-frequency percussive and pressure-controlled modes. Intensive Care Med 36:2125-2131

24. Phua J, Ang YL, See KC, Mukhopadhyay A, Santiago EA, Dela Pena EG, Lim TK (2010) Noninvasive and invasive ventilation in acute respiratory failure associated with bronchiectasis. Intensive Care Med 36:638-647

25. Boyer A, Vargas F, Hilbert G, Gruson D, Mousset-Hovaere M, Castaing Y, Dreyfuss D, Ricard JD (2010) Small dead space heat and moisture exchangers do not impede gas exchange during noninvasive ventilation: a comparison with a heated humidifier. Intensive Care Med 36:1348-1354

26. Fartoukh M, Lefort Y, Habibi A, Bachir D, Galacteros F, Godeau B, Maitre B, Brochard L (2010) Early intermittent noninvasive ventilation for acute chest syndrome in adults with sickle cell disease: a pilot study. Intensive Care Med 36:1355-1362 
27. Heunks LM, de Bruin CJ, van der Hoeven JG, van der Heijden HF (2010) Non-invasive mechanical ventilation for diagnostic bronchoscopy using a new face mask: an observational feasibility study. Intensive Care Med 36:143-147

28. Clouzeau B, Bui HN, Vargas F, Grenouillet-Delacre M, Guilhon E, Gruson D, Hilbert G (2010) Targetcontrolled infusion of propofol for sedation in patients with non-invasive ventilation failure due to low tolerance: a preliminary study. Intensive Care Med 36:1675-1680

29. Rocco M, Conti G, Alessandri E, Morelli A, Spadetta G, Laderchi A, Di Santo C, Francavilla S, Pietropaoli P (2010) Rescue treatment for noninvasive ventilation failure due to interface intolerance with remifentanil analgosedation: a pilot study. Intensive Care Med 36:2060-2065

30. Milesi C, Ferragu F, Jaber S, Rideau A, Combes C, Matecki S, Bourlet J, Picaud JC, Cambonie G (2010) Continuous positive airway pressure ventilation with helmet in infants under 1 year. Intensive Care Med 36:1592-1596

31. Cabello B, Thille AW, Roche-Campo F, Brochard L, Gomez FJ, Mancebo J (2010) Physiological comparison of three spontaneous breathing trials in difficult-to-wean patients. Intensive Care Med 36:1171-1179

32. Segal LN, Oei E, Oppenheimer BW, Goldring RM, Bustami RT, Ruggiero S, Berger KI, Fiel SB (2010) Evolution of pattern of breathing during a spontaneous breathing trial predicts successful extubation. Intensive Care Med 36:487-495

33. Perren A, Previsdomini M, Llamas M, Cerutti B, Gyorik S, Merlani G, Jolliet P (2010) Patients' prediction of extubation success. Intensive Care Med 36:2045-2052

34. Tan JA, Ho KM (2010) Use of dexmedetomidine as a sedative and analgesic agent in critically ill adult patients: a meta-analysis. Intensive Care Med 36:926-939

35. Jubran A, Lawm G, Kelly J, Duffner LA, Gungor G, Collins EG, Lanuza DM, Hoffman LA, Tobin MJ (2010) Depressive disorders during weaning from prolonged mechanical ventilation. Intensive Care Med 36:828-835

36. Jubran A, Lawm G, Duffner LA, Collins EG, Lanuza DM, Hoffman LA, Tobin MJ (2010) Post-traumatic stress disorder after weaning from prolonged mechanical ventilation. Intensive Care Med 36:2030-2037

37. Skrobik Y (2010) Praying for healthy minds and healthy bodies in ICU survivors. Intensive Care Med 36:1988-1989
38. Jaber S, Jung B, Corne P, Sebbane M, Muller L, Chanques G, Verzilli D, Jonquet O, Eledjam JJ, Lefrant JY (2010) An intervention to decrease complications related to endotracheal intubation in the intensive care unit: a prospective, multiple-center study. Intensive Care Med 36:248-255

39. Tadié JM, Behm E, Lecuyer L, Benhmamed R, Hans S, Brasnu D, Diehl JL, Fagon JY, Guerot E (2010) Post-intubation laryngeal injuries and extubation failure: a fiberoptic endoscopic study. Intensive Care Med 36:991-998

40. Prigent H, Garguilo M, Pascal S, Pouplin S, Bouteille J, Lejaille M, Orlikowski D, Lofaso F (2010) Speech effects of a speaking valve versus external PEEP in tracheostomized ventilator-dependent neuromuscular patients. Intensive Care Med 36:1681-1687

41. Via G, Lichtenstein D, Mojoli F, Rodi G, Neri L, Storti E, Klersy C, Iotti G, Braschi A (2010) Whole lung lavage: a unique model for ultrasound assessment of lung aeration changes. Intensive Care Med 36:999-1007

42. Remérand F, Dellamonica J, Mao Z, Ferrari F, Bouhemad B, Jianxin Y, Arbelot C, Lu Q, Ichai C, Rouby JJ (2010) Multiplane ultrasound approach to quantify pleural effusion at the bedside. Intensive Care Med 36:656-664

43. Sapru A, Curley MA, Brady S, Matthay MA, Flori H (2010) Elevated PAI-1 is associated with poor clinical outcomes in pediatric patients with acute lung injury. Intensive Care Med 36:157-163

44. Tissieres P, Myers P, Beghetti M, Berner M, Rimensberger PC (2010) Surfactant use based on the oxygenation response to lung recruitment during HFOV in VLBW infants. Intensive Care Med 36:1164-1170

45. Schaible T, Hermle D, Loersch F, Demirakca S, Reinshagen K, Varnholt V (2010) A 20-year experience on neonatal extracorporeal membrane oxygenation in a referral center. Intensive Care Med 36:1229-1234

46. Tingay DG, Copnell B, Grant CA, Dargaville PA, Dunster KR, Schibler A (2010) The effect of endotracheal suction on regional tidal ventilation and end-expiratory lung volume. Intensive Care Med 36:888-896

47. Carlisle HR, Armstrong RK, Davis PG, Schibler A, Frerichs I, Tingay DG (2010) Regional distribution of blood volume within the preterm infant thorax during synchronised mechanical ventilation. Intensive Care Med 36:2101-2108
48. De Luca D, Carnielli VP, Conti G, Piastra M (2010) Noninvasive high frequency oscillatory ventilation through nasal prongs: bench evaluation of efficacy and mechanics. Intensive Care Med 36:2094-2100

49. Farias JA, Fernandez A, Monteverde E, Vidal N, Arias P, Montes MJ, Rodriguez G, Allasia M, Ratto ME, Jaen R, Meregalli C, Fiquepron K, Calvo AR, Siaba A, Albano L, Poterala R, Neira P, Esteban A (2010) Critically ill infants and children with influenza A (H1N1) in pediatric intensive care units in Argentina. Intensive Care Med 36:1015-1022

50. Ejike JC, Kadry J, Bahjri K, Mathur M (2010) Semi-recumbent position and body mass percentiles: effects on intraabdominal pressure measurements in critically ill children. Intensive Care Med 36:329-335

51. Kaplan JM, Denenberg A, Monaco M, Nowell M, Wong H, Zingarelli B (2010) Changes in peroxisome proliferator-activated receptor-gamma activity in children with septic shock. Intensive Care Med 36:123-130

52. Sarafidis K, Soubasi-Griva V, Piretzi K, Thomaidou A, Agakidou E, Taparkou A, Diamanti E, Drossou-Agakidou V (2010) Diagnostic utility of elevated serum soluble triggering receptor expressed on myeloid cells (sTREM)-1 in infected neonates. Intensive Care Med 36:864-868

53. Agbeko RS, Holloway JW, Allen ML, Ye S, Fidler KJ, Pappachan J, Goldman A, Pontefract D, Deanfield J, Klein NJ, Peters MJ (2010) Genetic polymorphisms in the endotoxin receptor may influence platelet count as part of the acute phase response in critically ill children. Intensive Care Med 36:1023-1032

54. Dupuis C, Thomas S, Faure P, Gayot A, Desrumaux A, Wroblewski I, Debillon T, Emeriaud G (2010) Secondary adrenal insufficiency in the acute phase of pediatric traumatic brain injury. Intensive Care Med 36:1906-1913

55. Zimmerman JJ, Barker RM, Jack R (2010) Initial observations regarding free cortisol quantification logistics among critically ill children. Intensive Care Med 36:1914-1922

56. Jan SL, Lin SJ, Fu YC, Chi CS, Wang CC, Wei HJ, Chang Y, Hwang B, Chen PY, Huang FL, Lin MC (2010) Extracorporeal life support for treatment of children with enterovirus 71 infection-related cardiopulmonary failure. Intensive Care Med 36:520-527

57. O'Brien NF, Reuter-Rice KE, Khanna S, Peterson BM, Quinto KB (2010) Vasospasm in children with traumatic brain injury. Intensive Care Med 36:680-687 
58. Walter B, Aisenpreis K, Fritz HG, Soukup J, Eiselt M, Bauer R (2010) Age-dependent effects of gradual decreases in cerebral perfusion pressure on the neurochemical response in swine. Intensive Care Med 36:1067-1075

59. Fathali N, Lekic T, Zhang JH, Tang J (2010) Long-term evaluation of granulocyte-colony stimulating factor on hypoxic-ischemic brain damage in infant rats. Intensive Care Med 36:1602-1608

60. Carrai R, Grippo A, Lori S, Pinto F, Amantini A (2010) Prognostic value of somatosensory evoked potentials in comatose children: a systematic literature review. Intensive Care Med 36:1112-1126

61. Cogo PE, Poole D, Codazzi D, Boniotti C, Capretta A, Langer M, Luciani D, Rossi C, Bertolini G (2010) Outcome of children admitted to adult intensive care units in Italy between 2003 and 2007. Intensive Care Med 36:1403-1409

62. Straney LD, Clements A, Alexander J, Slater A (2010) Measuring efficiency in Australian and New Zealand paediatric intensive care units. Intensive Care Med 36:1410-1416

63. Rapoport J, Teres D, Lemeshow S, Gehlbach S (1994) A method for assessing the clinical performance and cost-effectiveness of intensive care units: a multicenter inception cohort study. Crit Care Med 22:1385-1391

64. Leteurtre S, Martinot A, Duhamel A, Gauvin F, Grandbastien B, Nam TV, Proulx F, Lacroix J, Leclerc F (1999) Development of a pediatric multiple organ dysfunction score: use of two strategies. Med Decis Making 19:399-410

65. Garcia PC, Eulmesekian P, Branco RG, Perez A, Sffogia A, Olivero L, Piva JP, Tasker RC (2010) External validation of the paediatric logistic organ dysfunction score. Intensive Care Med 36:116-122
66. Peeters B, Jansen NJ, Bollen CW, van Vught AJ, van der Heide D, Albers MJ (2010) Off-hours admission and mortality in two pediatric intensive care units without 24-h in-house senior staff attendance. Intensive Care Med 36:1923-1927

67. Chapman SM, Grocott MP, Franck LS (2010) Systematic review of paediatric alert criteria for identifying hospitalised children at risk of critical deterioration. Intensive Care Med 36:600-611

68. Naghib S, van der Starre C, Gischler SJ, Joosten KF, Tibboel D (2010) Mortality in very long-stay pediatric intensive care unit patients and incidence of withdrawal of treatment. Intensive Care Med 36:131-136

69. Iglesias JM, Lopez-Herce J, Urbano J, Solana MJ, Mencia S, Del Castillo J (2010) Chest compressions versus ventilation plus chest compressions in a pediatric asphyxial cardiac arrest animal model. Intensive Care Med 36:712-716

70. Lopez-Herce J, Fernandez B, Urbano J, Mencia S, Solana MJ, del Castillo J, Rodriguez-Nunez A, Bellon JM (2010) Terlipressin versus adrenaline in an infant animal model of asphyxial cardiac arrest. Intensive Care Med 36:1248-1255

71. Wildschut ED, Ahsman MJ, Allegaert K, Mathot RA, Tibboel D (2010) Determinants of drug absorption in different ECMO circuits. Intensive Care Med 36:2109-2116

72. Jack T, Brent BE, Boehne M, Muller M, Sewald K, Braun A, Wessel A, Sasse M (2010) Analysis of particulate contaminations of infusion solutions in a pediatric intensive care unit. Intensive Care Med 36:707-711

73. Kress JP, Gehlbach B, Lacy M, Pliskin N, Pohlman AS, Hall JB (2003) The long-term psychological effects of daily sedative interruption on critically ill patients. Am J Respir Crit Care Med 168:1457-1461
74. Wildschut ED, Hanekamp MN, Vet NJ, Houmes RJ, Ahsman MJ, Mathot RA, de Wildt SN, Tibboel D (2010)

Feasibility of sedation and analgesia interruption following cannulation in neonates on extracorporeal membrane oxygenation. Intensive Care Med 36:1587-1591

75. Chrysostomou C, Komarlu R, Lichtenstein S, Shiderly D, Arora G, Orr R, Wearden PD, Morell VO, Munoz R, Jooste EH (2010)

Electrocardiographic effects of dexmedetomidine in patients with congenital heart disease. Intensive Care Med 36:836-842

76. Plumpton KR, Anderson BJ, Beca J (2010) Thyroid hormone and cortisol concentrations after congenital heart surgery in infants younger than 3 months of age. Intensive Care Med 36:321-328

77. Kyle UG, Coss Bu JA, Kennedy CE, Jefferson LS (2010) Organ dysfunction is associated with hyperglycemia in critically ill children. Intensive Care Med 36:312-320

78. Preiser JC (2009) NICE-SUGAR: the end of a sweet dream? Crit Care 13:143

79. Vlasselaers D, Milants I, Desmet L, Wouters PJ, Vanhorebeek I, van den Heuvel I, Mesotten D, Casaer MP, Meyfroidt G, Ingels C, Muller J, Van Cromphaut S, Schetz M, Van den Berghe G (2009) Intensive insulin therapy for patients in paediatric intensive care: a prospective, randomised controlled study. Lancet 373:547-556

80. Macrae D, Pappachan J, Grieve R, Parslow R, Nadel S, Schindler M, Baines P, Fortune PM, Slavik Z, Goldman A, Truesdale A, Betts H, Allen E, Snowdon C, Percy D, Broadhead M, Quick T, Peters M, Morris K, Tasker R, Elbourne D (2010) Control of hyperglycaemia in paediatric intensive care (CHiP): study protocol. BMC Pediatr 10:5 